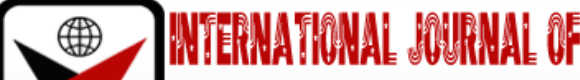

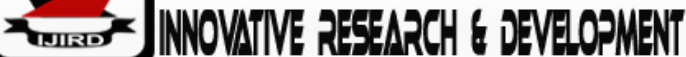

ISSN 2278-0211 (Online)

\section{Fabricating a Press Mould for Producing Letters for Teaching Illustration/Aparatus}

\author{
Ruth Mataba Gadzama \\ Lecturer, Department of Industrial Design, \\ Modibbo Adama University Yola, Adamawa State Nigeria \\ Samson Yerima Mshelia \\ Ph.D. Student, Department of Industrial Design, \\ ABU Zaria, Kaduna state Nigeria
}

\begin{abstract}
:
Teaching apparatus are materials that classroom teacher uses to help students understand the concepts she introduces during lessons. These teaching apparatus can take many forms, from beans students count and sort while learning simple kindergarten math to photos of famous people and places introduced during a middle school history lesson. Materials usually employed in the production of teaching apparatus and learning include, plastic, Wood, paper, leather etc. These materials may be too heavy as found in Wood, easily perishable as in paper, dangerous in plastic. Clay in terms of properties and suitable to children learning is versatile, durable and can be painted in different colors to attract children at primary school stage. Since clay is light, easily manipulated its usage in making teaching apparatus will help reduce weight, promote durability of teaching and learning materials, and also reduce the high cost of imported materials such as charts, plastic and electronically operated teaching and learning apparatus for pre-school education. The researcher employed the use of product development using descriptive and experimental methods. Clay was identified to be a convenient material for making teaching apparatus for primary school education since it has been found to be readily-accessible easily manipulated, remarkably light. The researcher recommends classroom' should have a plentiful supply of clay instructional materials and object. Which have educational value and benefit when children play with them, schools, parent, guardians, teachers are encourage to make ample provision for stimulating children curiosity through the use of clay teaching apparatus.
\end{abstract}

Keywords: Properties, compatibility, promote, electronically, experimental, convenient, manipulated

\section{Introduction}

These teaching apparatus can take many Ways of shapes, from beans students count and sort while learning simple kindergarten math to photos of famous people and places introduced during a middle school history lesson. Choosing apparatus that match with student grade levels, corresponding interests and abilities helps to engage students beyond a simple lecture format. From manipulative to media, these teaching apparatus used in context can complement classroom instruction. The reason for using Apparatus in teaching is to stop student not to be board in learning.

Famwang (2003) stated that the search for apparatus to make teaching and learning simplify and effective has been long among educators. The teacher needs to know which instructional materials and pieces of equipment are appropriate and relevant for the teaching-- learning situation. Owen (1973) stated that instructional materials are an educator's tools. They are used in classrooms or studios throughout the world to improve teaching and effect learning. Everything 'should be done to get the educational institutions to fulfill their potentials, not by providing the schools with endless - but in the end trivial- -options, but by supplying effective alternative for individual learners

Bassey, (2006); Bakinde, '(2006) and Ada, (2006) affirmed the role of ceramics in vocational enterprises and career development, cultural development and promotion, socio-cultural, economic empowerment and' capacity building, and its contribution to industrial and technological development and promotion in Nigeria. Many toys and teaching apparatus in the market use plastic for their production. Plastic toys are extremely common nowadays, partly because of their demand due to low average prices, but they have health risks that come with them. Many toxins are absorbed into our bodies through the mouth and. since babies do a lot of exploring with their mouths, this means that our children are particularly at health risk. BPA and phthalates are examples of toxic compounds commonly found in a range of different plastics. Although government guidelines are getting stricter with regards to what materials toys can be made out off, there are still many toys and instructional material on our shelves containing more than the recommended maximum amount of these ingredients. Phthalates are now banned from plastic toys in the USA.

A paper titled, 'Fine Motor Skills and Early Comprehension of the World: Two New School Readiness indicators', by Claire E. Cameron et al, published in Developmental Psychology (2010) found that 'having good fine motor skills in pre- 
school is a strong predictor of a child's later academic achievement in reading and math'. So, learning how to accurately use her fingers to get just the right shape out of clay, can help your child improve her fine motor skills and be better at academics. In pottery, press molding refers to the process in which clay is forced into a mold in order to take on a certain shape. Once the mold is removed, the piece produced is a uniform replication of the inside of the mold (similar to casting with metalwork). Press molds work great when reproducing multiple pieces of ceramics-from bowls to plates to tiles. Using this method, you can also create pottery shapes that would be difficult to throw on the wheel. Repeating the shape again and again by using a mold also saves you time that you can otherwise spend on the finishing touches.

Knowing how valuable clay is to children's achievements, with the belief that clay is an essential element for nurturing children's growth is the reason behind the_design and construction of clay alphabets and shape as teaching for children's instruction.

\subsection{Statement of the Problem}

Clay deposits around us need to be harnessed for the production of teaching apparatus. The research explores the use of clay as an alternative material for making teaching apparatus, assist pre-school teaching and learning. Teaching apparatus play a vital role in teaching and learning at various levels of education, especially at the pre-school level Where children need to build a strong foundation to ground them firmly for mainstream education. Such instructional apparatuses are usually made from Home materials that include plastic, Wood, paper, leather. It has been observed that teaching and learning materials made in plastics are usually imported into the country at high cost to the detriment of the economy of the nation. Additionally, many types of plastic materials _involved are not biodegradable when they are disposed of. Wood resources may be used, but its sources are being depleted, and consequently, scarce and expensive. Metals are not conducive for instructional materials meant for pre-school children because of their Weight, toxicity and tendency to injure children. Paper is highly perishable and easily wears out, especially in the hands of pre-school pupils. Conversely, clay is versatile, durable, pliable, and bleachable and can be dyed in various colors for easy attraction. Children at the pre-school stage are highly curious and easily become attracted to bright colors.

\subsection{Aim of the Study}

The aim of the paper is to explore the Workability; suitability and feasibility of clay for the design and construction of press molded shapes and alphabets as Teaching Apparatus

\subsection{Objectives of the Study}

The specific objectives of the paper are too;

- To formulate workable stoneware clay bodies for press molded alphabets and shapes

- To design a learning manual on clay press moulds for parents, guardians and teachers

- This research seeks to design the 26 alphabets and shapes (square, triangle, star, and cross) for primary school education.

\subsection{Significance of the Studies}

According to Grim (1968), the numerous minerals formed from the geologic orientation of the earth's crust provide mainly the non-metallic minerals that can be exploited as raw material for ceramics production. The paper helped to improve the use of clay in making teaching apparatus for teaching and learning in the nation's primary schools. It also helped ministry of Education to reduce the cost of imported materials such as charts, plastics and electronically operated teaching materials. The paper encourages teachers to use available clay as resource materials without relying on foreign ones.

\section{Methodology}

\subsection{Introduction}

Survey, design and construction was used in carrying out the research, detailed description ofTools, items and material in executing the project.

\subsection{Material and Equipment}

In developing this research, the materials used are, cottle, computer (Corel draw), modeling tools, Water, mixing bowl, weighing scale.

- Cottle: a band or Wall typically of wood that encircle an object to be molded and determine the outer extremity of the completed mold. 


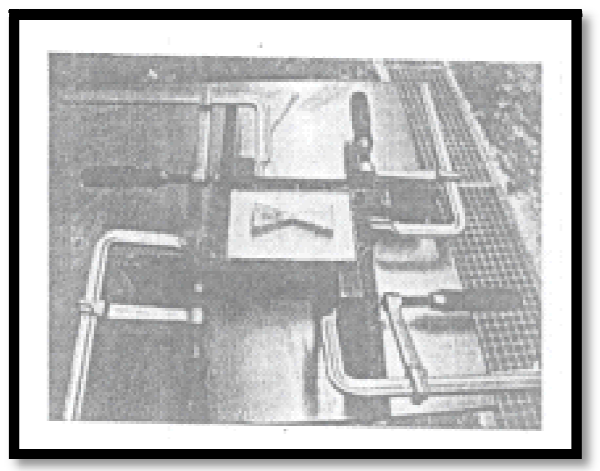

Figure 1: Cottle

Source, Internet Download

- Adobe illustrator interface: Adobe Illustrator is a vector graphics editor developed and marketed by Adobe Inc. Originally designed for the Apple Macintosh, development of Adobe Illustrator began in 1985. Along with Creative Cloud (Adobe 's shifts to monthly or annual subscription service delivered over the Internet), Illustrator CC was released.

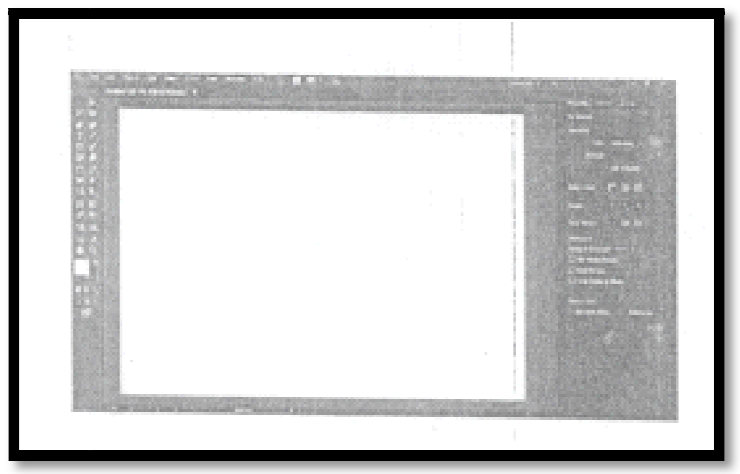

Figure 2: Adobe Illustrator Interface Source: Internet Download

- Modeling tools: modeling tools are basically molded set, use for either designing, inscribing, on wares.

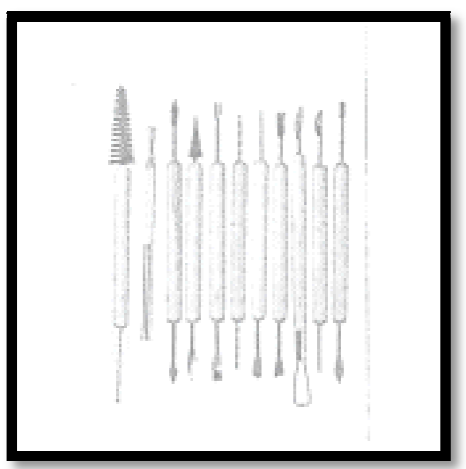

Figure 3: Modeling Tools

Source: Internet Download

- Water: this is a transparent chemical substance, which is the main constituents of the earth stream, lakes and ocean. that will be used in mixing the plaster of Paris (pop).

Mixing bowl: Mixing container that is large enough to hold to Water and plaster. Plasticcontainers are nice because you can deform them afterwards to break away the hard plaster and re-use the container. 


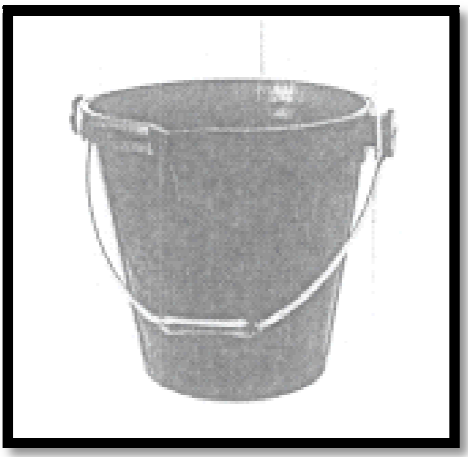

Figure 4: Bowl Source Internet Download

Weighing scale used for weighing the ratio of water to plaster of Paris.

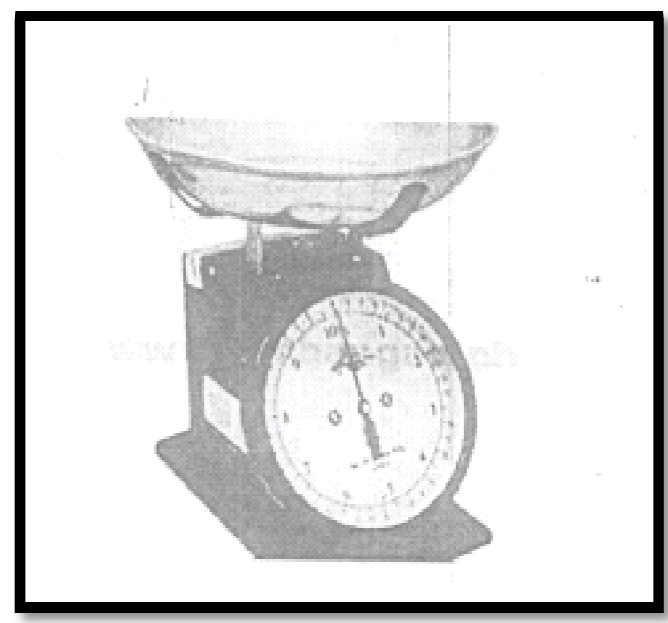

Figure 5: Weighing Scale

Source, Internet Download

Measuring cup that can be used to measure out 3 parts of plaster to 1-part water

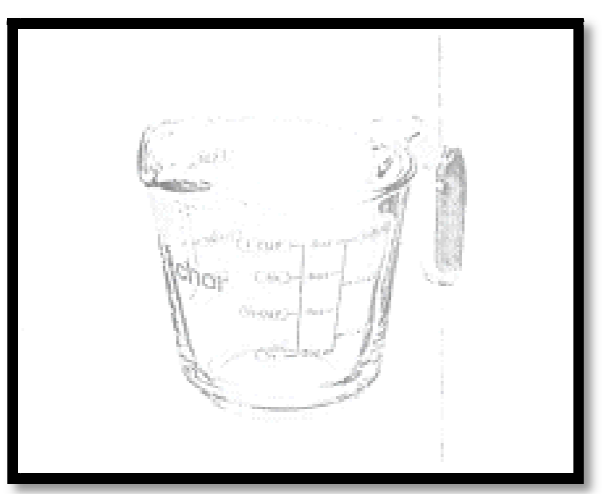

Figure 6: Measuring Cup

Source, Internet Download

\subsubsection{Raw Materials}

The major raw materials for casting are, ball clay, feldspar, quartz, plaster of Paris and kaolin/china clay

- Ball clay: A line textured clay used in ceramic

- Feldspar: an abundant rock-forming mineral typically occurring as colorless or pale-colored crystals and consisting of alum inosilicates of potassium, sodium, and calcium 


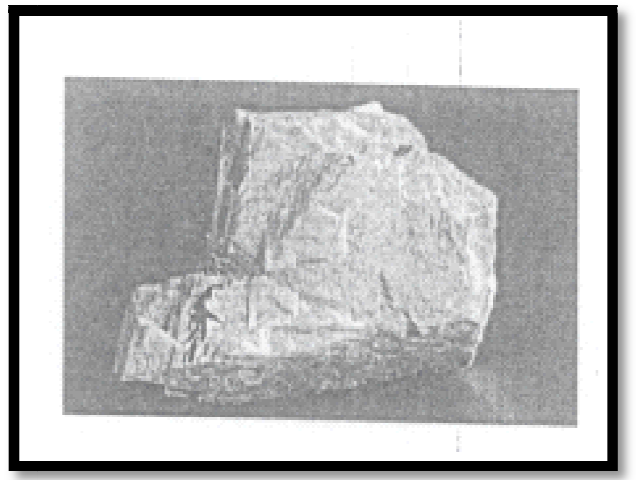

Figure 7: Feldspar

- Quartz: Quartz is a mineral composed of silicon and oxygen atoms in a continuous framework of $\mathrm{SiO}_{4}$ siliconoxygen tetrahedra, with each oxygen being shared between two tetrahedra, giving an overall chemical formula of $\mathrm{SiO}_{2}$

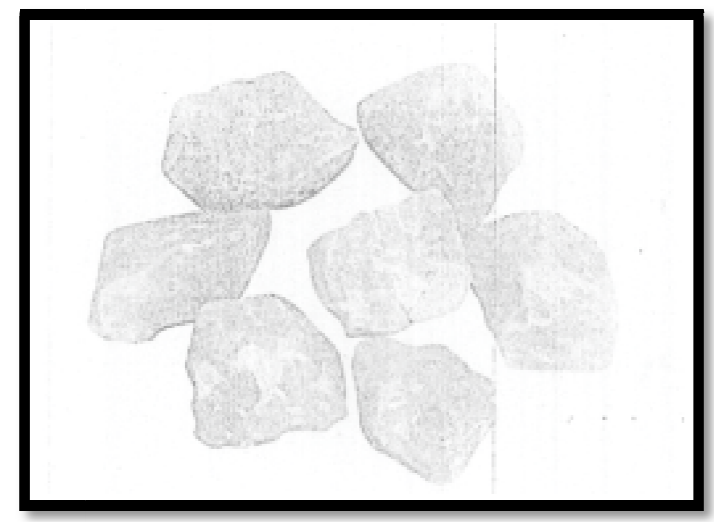

Figure 8: Quartz

- Plaster of Paris: is a type of plaster made from powder and water which dries quickly it is used to make plaster cast.

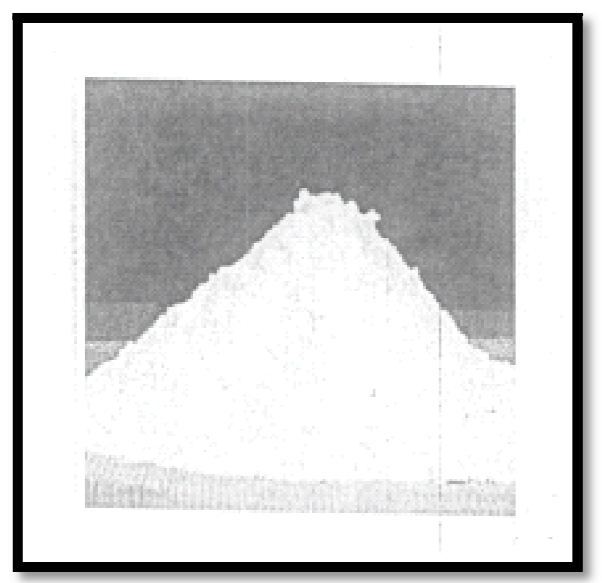

Figure 9: Plaster of Paris

- Kaolin / china clay: Kaolin, also called china clay, soft: White clay that is an essential ingredient in the manufacture of china and porcelain and is widely used in the making of paper, rubber, paint, and many other products. Kaolin is named after the hill in China (Kao-ling) from which its R.M.G(2015) 


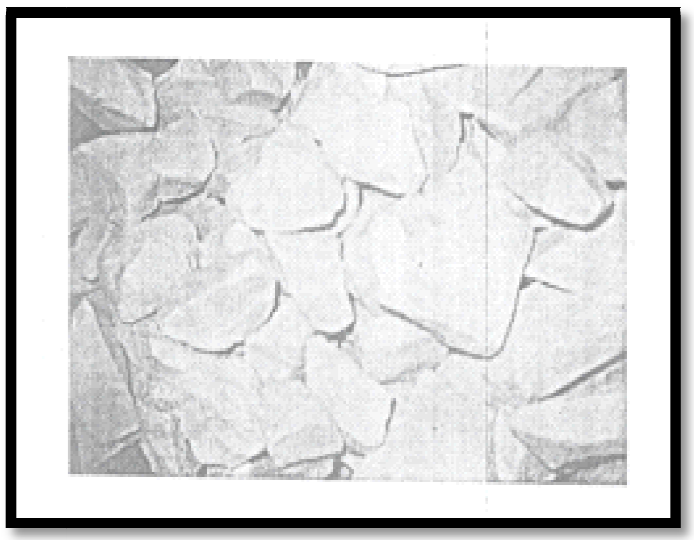

Figure 10: Kaolin

\subsubsection{Procedurefor Designing and Construction of Shapes and Alphabet}

One important thing to know is that the ratio of water to gypsum in the mold suspension will have a direct effect on the time it takes to remove water from the cast. The advantage of this technique is that it's inexpensive and timeefficient for casting complex parts when compared to other conventional methods.

When Gypsum is mixed with water it hardens. The reaction is very exothermic, the mixture heats up quickly. The chemical reaction is exothermic and may cause skin irritation. Wash hands if some of the mixture comes in contact with skin. The increase in the temperature of the mixture is due to the physical and chemical changes the gypsum undergoes when it interacts; with water and starts to harden.

Plaster of Paris is low cost, easy to use, and makes good castings. Plaster of Paris comes as an easy-to-mix formula that mixes with water and dries to a dense, durable, and smooth and bubble free finish. Plaster of Paris is a great material to use for basic castings and molds 'and art projects because it is simple to mix and use. , The Plaster of Paris sets in a few minutes although it takes an hour before it is ready to be removed from the mold. takes 24-48 hours to fully cure. Using Plaster of Paris is easy, but there are procedures to follow that will make you successful in your plaster castings.

The ideal ratio for a Plaster of Paris mixture is 3 parts Plaster of Paris powder toil part water by weight or volume. Measure out the water and pour it into your mixing container. Some recipes suggest 2 parts plaster to water, but this will create a niuch weaker plaster casting. The thicker you can be while still being able to pour the better. Start with 3 to $l$ ratio and if necessary add small amounts of water to make it easier to pour

\subsubsection{Sample of Alphabet and Shapes}

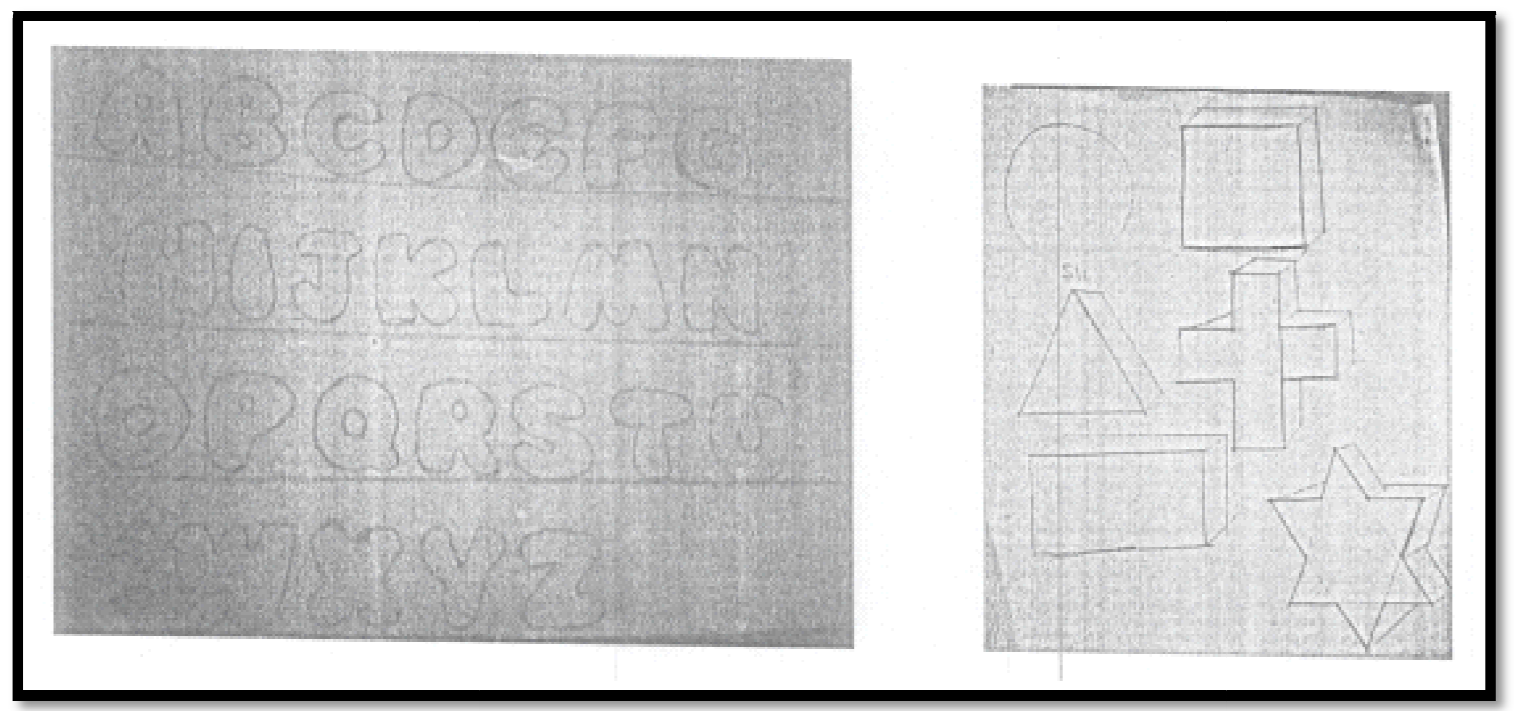

Figure 11: Studio Practice I

\subsubsection{How to Make the Mold?}

After picking, wedging or kneading the clay, I made a slap of 6 X 5 inches slap, using a roller to make it flat. I now transfer the design from the printed lettering 1 made on the adobe illustrator to the slap and allow to leather hard a little. And cutoff each letter separately using the modeling tools. Next was to now prepare the cottle and get ready for casting. 


\subsection{Execution of Activities}

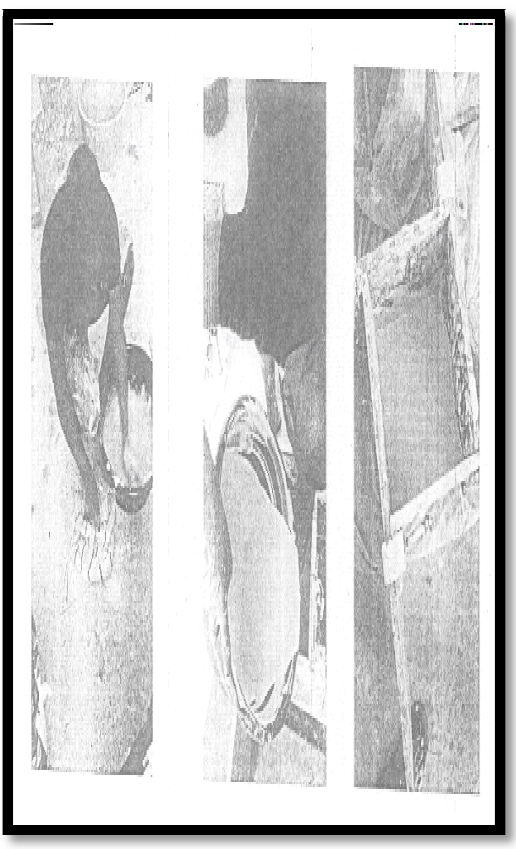

Figure 12: Making and Pouring Mixed P.O.P into the Cottle

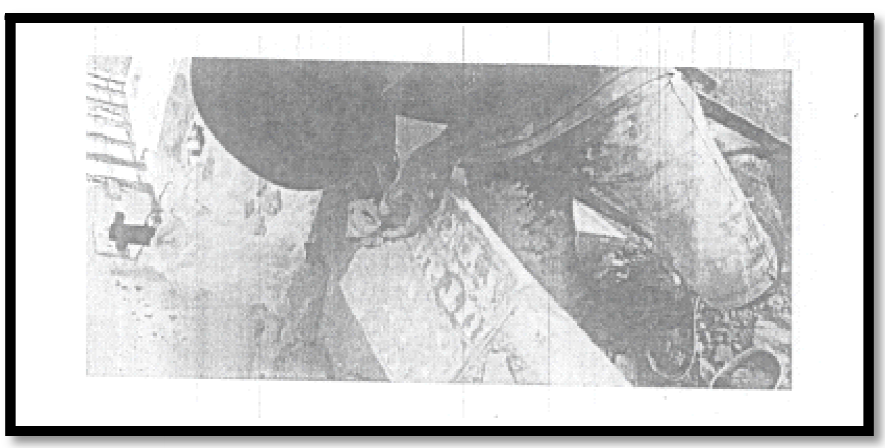

Figure 13: Press Molding Alphabet from Mold

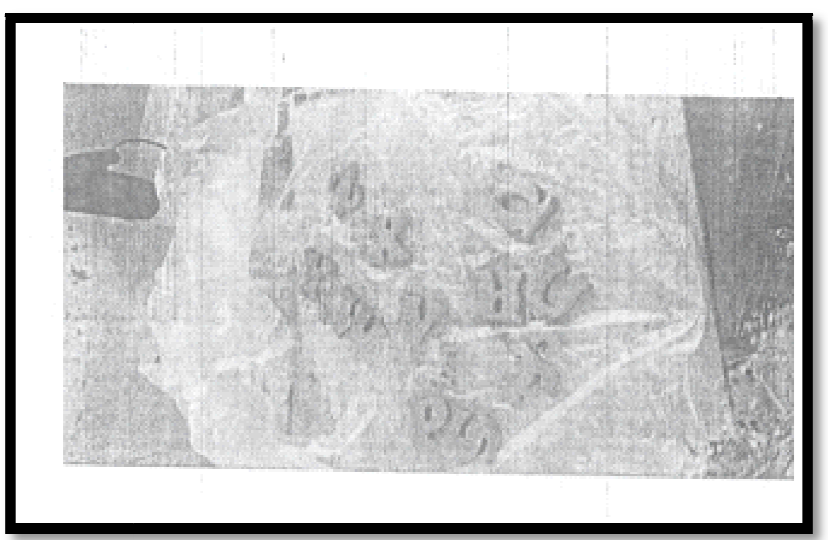

Figure 14: Sample of Already Press Alphabet 


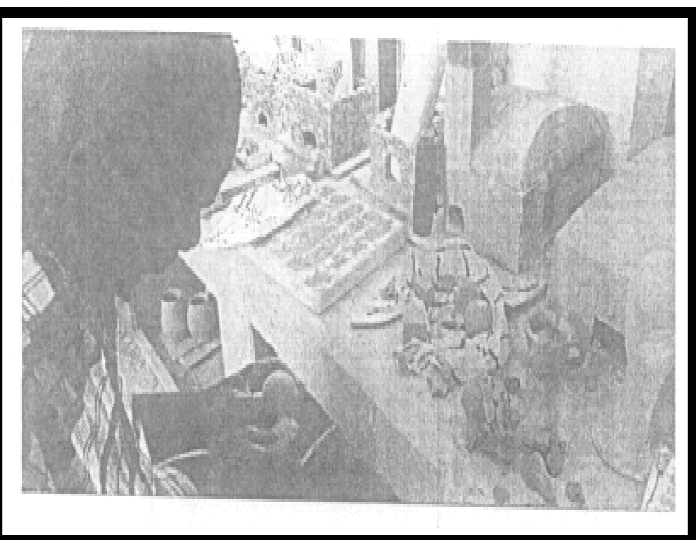

Figure 15: Making Various Shapes

\section{Discussion and Findings}

\subsection{Dimensioning}

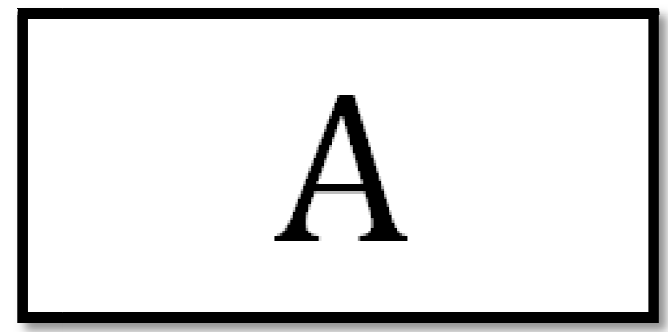

Figure 16: Dimensioning

The length and breadth of each letter is $4 \mathrm{~cm} * 4 \mathrm{~cm}$ :

\subsection{Manual for clay alphabet and shapes}

\subsubsection{How to Make Alphabet from the Mold?}

After kneading or wedging the clay, small amount of clay is cut and press on the desired letter, flatten it and allowed to stay for approximately 5(Five) minutes, then you use another soft clay to press and remove it. As shown below

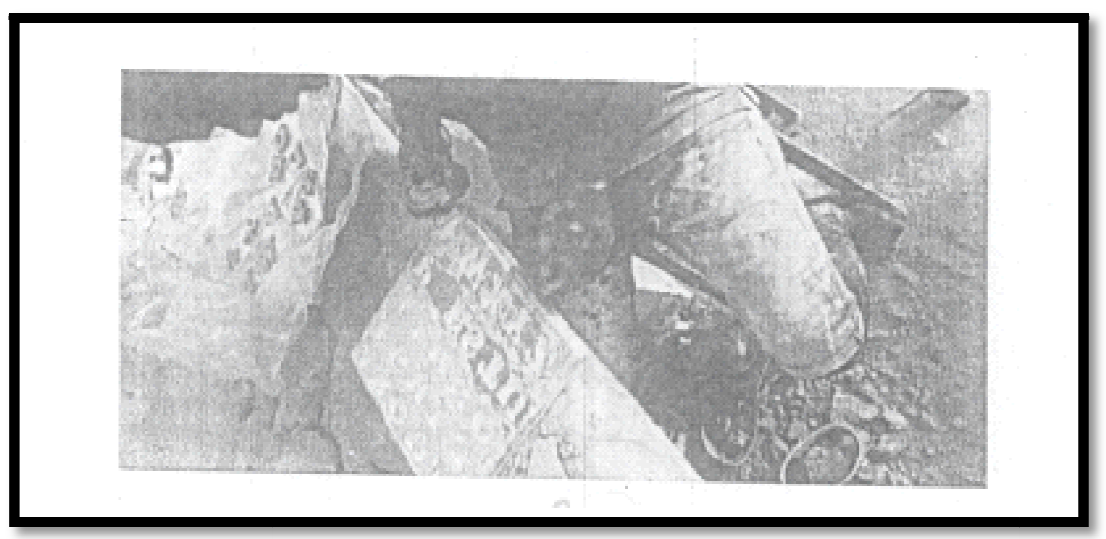

Figure 17: Removing Letters from the Mold

\subsubsection{How to Use the Letters?}

- Clay is a fined grained natural rock that when mixed with water becomes sticky and plastic.

- This, alphabets and shapes have been fire to a temperature around 800 degree

- The letter and shapes can be arranged on a flat surfaced to learn spelling of words, recite the

- A, B, C and learn different shapes.

- The letter contain magnet that can be attached to the board.

- After used the letter and shapes should be return to the box and kept in a save place 


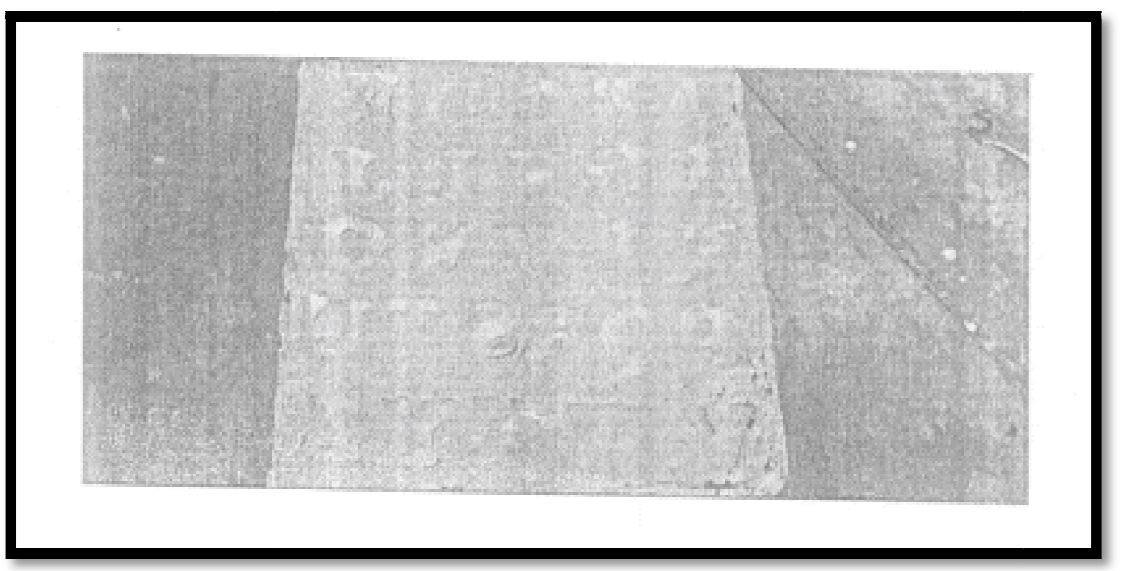

Figure 18: Mold of Alphabet

\subsubsection{Findings}

Clay been very lightweight, durable, flexible, plastic be manipulated into a number of Ways for making primary school teaching apparatus into various kind, sizes and shapes Clay can be molded into endless forms. Humans have been making objects out of clay for ages- pots, plates, bowls, sculptures, slates, and so on. The facts that we have been able to create so many different objects out of clay is a testament to its versatility as a medium. One important benefit of clay is the role it plays in early childhood education.

Clay, and its necessity to be touched, is at once familiar to children. The sensory experience they encounter when the handle clay are numerous and as they experience the texture and feel of the clay

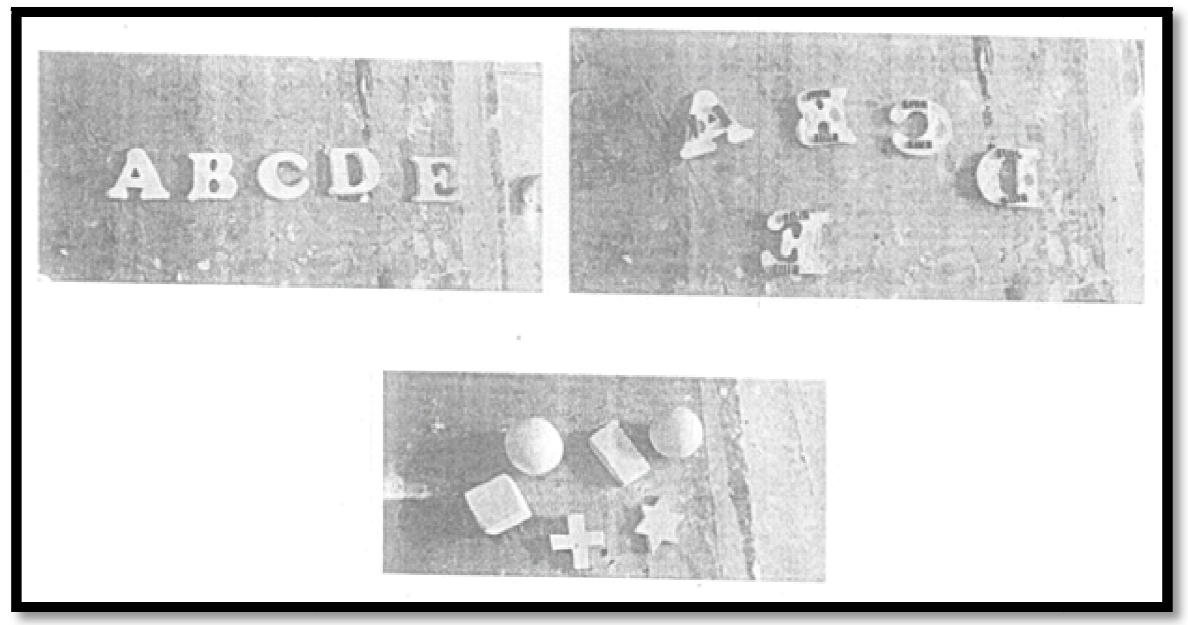

Figure 19: Sample of Shapes'

\subsubsection{Discussion}

From the research done indicates that clay found around us, sourced to make alphabet and shapes confirmed that Clay can be easily manipulated to achieve a desired shape, form and sizes. The teaching apparatus produced was tested for the following: attractive, durable, safety to use, fitness for the purpose of clay teaching.

\section{Summary and Conclusions}

\subsection{Summary}

The research explored the use of clay for designing and producing of teaching apparatus for primary school education. clay was used in place of existing materials such as plastics, paper, metal and imported articles. Some of these traditional materials are not biodegradable, highly perishable, are heavy, toxic and have tendency to injure children, clay is mostly available. More importantly, clay is versatile, durable, flexible, and lightweight.

\subsection{Conclusion}

The research successfully assessed the suitability of clay for teaching apparatus on teaching and learning at the primary school level of education. The research found out that clay is suitable for use as instructional materials to apparatus teaching and learning because clay is; Durable. Easily Manipulated. Safe to use and Fit for the purpose.

\section{References}

i. Alasa (2005). Fundamentals of Ceramics. Moramon Bros. Ent. Benin City, Nigeria. Aliyu, A. (1995). Industrialization in Nigeria. 
ii. Ari, E., \&Yrlmaz, V. (2017). Constuner Attitudes on the Use of Plastic and Cloth Bags. Environment, Development and Sustainability40 Dilli's Venture Limited, Lagos, Nigeria

iii. R.M.G (2015) Ph.D. thesis Utilization Kankara and graycast iron, for the production of composite refractory.

iv. Bassey, E A. (2006). Studies on Pottery Heritage: Focus on lbibio Ceremonial Pots.Ashaku Journal of Ceramics, 3, Damsa Press, Zaria, Nigeria

v. Brink, P., Schweitzer, J., Gionfra, S., \& Watkins, E. Single Use Plastics. 0.40

vi. Corben, R. (2017, Jun 22,). Asia's Booming Plastics lndustry Prompts Ocean Pollution Fears Asia News Monitor Retrieved from https ://www.voanews.com/a/asia; plasticsindustry/3 911586 .html40

vii. Danielsson, M. (2017). The Plastic Bag Ban in Rwanda: Local Procedures and SuccessiitlOutco1nes40.

viii. Ewule, E.E (2004). Ceramics in Education Overview of General Aft with Pottery Craft in Schools Colleges and Ceramics in University Education. Ashaku Journal

ix. Ewule, E.E. (2006) Issues that Hampers the Progress of Ceramics Production In 40

x. Freytas-Tamura, K. D. (2017). Public Shaming and Even Prison for Plastic Bag use in Rwanda. 40

xi. Gukas, H.J. (2005) Towards a Model Curriculum for Ceramics Teaching in Nigeria.

xii. Ashaku Journal of ceramics 1/3 Damsa Press: Zaria, Nigeria.

xiii. Gukas, I-LJ., and Dattri, V.C (2001) The Art of Pottery. Jos: CC Communications.

xiv. Hamer, P. (1975) Potters Dictionary of materials and Techniques London: Pitman Haruna, A. 1. (1998). Geology, Geochemistry and origin of Gypsum Mineralization in North Eastern Nigeria (Chad Basin). 40

xv. Mode, A.W and Amohi, J .O (2006) Geochemistry of Clay and their applications in the ceramics industry. Ashaku Journal of ceramics, Vol. 3, Damsa Press Zaria Nigeria.

xvi. Murray(1997), transportation of natural clay minerals at elevated temperature and pressure

xvii. Musa, H., Hayes, C., Bradley, M., Clayson, A., \&Billihrand, G. (2013). Measures Aimed at Reducing Plastic Carrier Bag Use: A Consumer Behavior Focused Study40

xviii. Norton, T.H. (1956) Ceramics for the Artist-Potter New York: Addison - Wesley Publishing Company40

xix. 0wen, B.K (1973) Sharper Tools for Better Learning National Association of Secondary School Principals. 40 